\title{
Preweanling and adult rats treat conditioned light-tone combinations differently
}

\author{
PHILIPP J. KRAEMER \\ University of Kentucky, Lexington, Kentucky \\ and \\ NORMAN E. SPEAR \\ State University of New York, Binghamton, New York
}

\begin{abstract}
Ontogenetic differences in processing light-tone compounds were discovered in preweanling (17-day-old) and adult (60-80-day-old) rats. Suppression of general activity was used as an index of the magnitude of conditioned fear following a single training session in which a CS + was paired with mild footshock. In Experiment 1, rats were trained on discriminations in which the CSconsisted of a light and the CS+ was either a tone alone (simple discrimination) or a light-tone compound (simultaneous feature-positive discrimination). Adults and preweanlings given each type of discrimination were then tested for fear of the CS- and a target stimulus (tone alone or light-tone compound). Adults in all groups displayed greater fear of the target than of the CS-. Preweanlings, however, discriminated the CS- from the target only when the target was the same as the original CS+. Experiment 2 revealed that age-related differences in conventional stimulus generalization is not a likely explanation for the pattern of results found in Experiment 1. Experiment 3 revealed age-related differences in expressed fear of a serial feature-positive discrimination; adults, but not preweanlings, showed greater fear of the compound than of the CS-. Alternative interpretations of the results from these experiments are discussed, and the general conclusion is that adults appear more inclined to process elements of a compound stimulus selectively, whereas preweanlings seem more likely to process the compound unselectively, with roughly equivalent processing of each element.
\end{abstract}

There is substantial evidence of important age-related differences in the performance of rats during both acquisition and retention of simple learning episodes (Kail \& Spear, 1984; Spear \& Campbell, 1979). Ignoring much of the research prior to 1950 , which seems prudent given the methodological and design limitations characteristic of that research (Campbell, 1967), the contemporary trend has been for the performance of younger rats-preweanlings and weanlings-to be inferior to that of adults, although important exceptions do exist (Spear \& Molina, 1987). The younger rats' apparent inferiority has been manifested in three ways: a failure to learn in situations in which adults show learning (Moye \& Rudy, 1985; Rudy, Vogt, \& Hyson, 1984); an impairment in learning, relative to adults, with respect to learning rate and asymptotic level of performance (Amsel, 1979); and, perhaps most robust of all, a greater rate of forgetting (Camp-

The present research was supported by grants from the National Institute of Mental Health (1 RO3 MH42992 to P. J. Kraemer and 1 RO1 MH35219 to N. E. Spear). The authors wish to acknowledge the assistance of Cindy Pudiak. We also wish to thank Norman G. Richter for technical assistance, and Teri Tanenhaus for preparation of the manuscript. Requests for reprints may be addressed to either Philipp J. Kraemer, Department of Psychology, University of Kentucky, Lexington, KY 40506, or Norman E. Spear, Department of Psychology, State University of New York at Binghamton, Binghamton, NY 13901. bell \& Coulter, 1976; Campbell \& Spear, 1972; Coulter, 1979). Much of the contemporary interest now concerns detailed analysis and explanation of these ontogenetic differences. The success of this pursuit is not only relevant to the study of ontogeny, but it can also contribute significantly to our general understanding of animal information processing.

One of the most intuitively appealing hypotheses has been that the relative performance inferiority of the younger rat is due to corresponding deficiencies in its neurological development (Coulter, 1979). Simply stated, the idea is that if the immature brain does not function at optimum capacity, then its effectiveness in processing information will be commensurately constrained. In terms of a computer metaphor, this perspective conceptualizes the inferiority of the younger rat as a matter of "hardware": deficits in neural functioning lead to deficits in information processing. A popular version of this approach is the memory-systems view. It assumes that there are qualitatively different kinds of memory, and that each kind is associated with a different neurological system, usually implicating a specific brain structure or structures. The underdevelopment of these structures in immature animals is assumed to underlie the behavioral deficits found in learning and memory tasks (Amsel, 1986; Bachevalier \& Mishkin, 1984; Nadel \& Zola-Morgan, 1984). Although this approach is certainly viable, and may account for 
many age-related differences in learning and memory, there are alternatives that may be equally plausible.

Extending the computer metaphor, another possibility is that some ontogenetic differences may be based on "software" rather than hardware. Specifically, younger rats may process information differently than do adults. According to this position, despite the relative immaturity of the younger rat's neurological status, its brain may be sufficiently developed to process information but may do so in a manner different from that of adults. Processing differences could appear in several forms, including age-related differences in representational content, the processes of storage and retrieval, the organization of memory, and the behavioral mechanisms that underlie the expression of acquired behavior. As an example of a content difference, it has been argued that younger and older rats may represent different numbers and kinds of attributes within a learning episode (Gordon, 1979; Spear, 1979; Spear \& Kucharski, 1984b). Such content differences may then translate into differences in both the immediate expression of a learning episode (i.e., the degree or rate of learning) and subsequent retrieval of that episode (Spear, 1973, 1978).

One approach to the experimental analysis of age-related differences in representational content has been to study the ontogeny of stimulus selection (Spear \& Kucharski, 1984a). The strategy is to test conditioning to compound and element stimuli as a function of age. Pavlovian conditioning has often been used in which either a singleelement or a compound conditioned stimulus (CS) is paired with an aversive unconditioned stimulus (US), such as mild footshock or injection of $\mathrm{LiCl}$. Response to the CS or some related stimulus is then evaluated, usually with a simple stimulus-preference test. Studies of this nature have revealed a number of ontogenetic differences in such phenomena as overshadowing, potentiation, and withincompound learning (Hinderliter \& Misanin, 1988; Spear \& Kucharski, 1984a, 1984b). The general trend in these studies has been for younger rats to display a greater likelihood of configuring compound stimuli than do adults. This effect roughly resembles the tendency for younger children to treat stimuli in an integral rather than a separable fashion (Garner, 1970; Shepp, 1983; Spear, 1984).

As an illustration of the apparent configuring, Spear \& Kucharski (1984b) described an experiment in which preweanlings ( 18 day old) and adults (60 days old) were exposed in various ways to a compound CS paired with $\mathrm{LiCl}$. In the most pertinent conditions, the compound consisted of two flavors-coffee and sucrose-presented simultaneously. After conditioning, separate groups at each age were given nonreinforced presentation of one or both of the two elements presented separately, or of the compound itself. These extinction procedures were found to have differential effects at the two ages. Preweanlings showed little reduction in the aversive strength of the compound when extinction was to either or both elements presented singly, despite an extinction effect with nonreinforced exposure to the compound itself that was as substantial as adults'. Adults, however, showed a marked reduction in responses to the compound after nonreinforced exposure to the elements presented singly. One interpretation of these results is that the preweanlings showed a greater tendency to configure the compound flavors and to treat them as distinct from the elements, whereas the adults relied on elementistic processing, in which the compound was decomposed into its elements and conditioning and extinction accrued to each element independently (Kehoe \& Gormezano, 1980).

The present study was designed to analyze further the issue of age-related differences in stimulus selection. It differs from previous research in two important respects. First, the stimulus elements consisted of a light and a tone. The majority of ontogenetic studies in this area have relied on flavor and odor stimuli. Our use of light-tone compounds was intended to obviate some problems and limitations inherent with flavor and odor stimuli. For example, lights and tones can be controlled easily and can be presented as punctate stimuli, which is difficult to do with odors and tastes; these stimuli may persist well beyond their nominal termination. It is also more difficult to control the interaction between elements within flavor and odor compounds. Combining Odor A with Odor B may yield Odor $C$, a distinctly different stimulus, rather than a combination of $\mathrm{A}$ and $\mathrm{B}$; that is less likely with lighttone compounds.

A second feature that distinguishes this study from previous investigations is that we attempt to assess stimulus selection within the context of discrimination learning. Our goal was to develop a situation in which we could distinguish representational content from the learning process itself. We sought to accomplish this by employing a task that would yield comparable discrimination learning in preweanlings and adults, but one in which subsequent manipulation of the nature of the test stimuli would reveal ontogenetic differences in the content of the representations used to solve the discrimination.

\section{EXPERIMENT 1}

In this experiment, we examined acquisition and expression of a conditioned fear discrimination in preweanling (17-day-old) and adult (60-80-day-old) rats. Moye and Rudy (1985) devised a procedure for studying Pavlovian fear conditioning in young rats that obviates many of the methodological obstacles found with other procedures. Their approach is to measure general activity or movement within a small chamber, using an ultrasonic motion detector. This device outputs discrete pulses that are positively correlated with air disturbances produced by the animal's movement. Fear conditioning is assessed as the degree of suppression in ongoing activity during presentation of a CS.

The design of Experiment 1 can be seen in Table 1. Four separate groups of preweanlings and adults were trained on one of two discriminations: a simultaneous feature-positive discrimination or a simple discrimination. 
Table 1

Design of Experiment 1

\begin{tabular}{llcccc}
\hline & & & & \multicolumn{2}{c}{ Test Stimuli } \\
\cline { 5 - 6 } Group & Discrimination & CS + & CS & Target & CS- \\
\hline LT-LT & Feature positive & LT & L & LT & L \\
LT-T & Feature positive & LT & L & T & L \\
T-T & Simple & T & L & T & L \\
T-LT & Simple & T & L & LT & L \\
\hline
\end{tabular}

Note- $-\mathrm{L}=$ light, $\mathrm{T}=$ tone.

All groups were exposed to a random order of CS+ trials, which were always followed by footshock, and CStrials, which were never followed by footshock. The CSwas a light alone for all groups, but the groups differed with respect to the nature of the CS+. The two groups given the feature-positive discrimination (Groups LT-LT and LT-T) received a simultaneous light-tone CS+, whereas the two groups given the simple discrimination (Groups T-T and T-LT) were trained with a tone alone as the CS+. Each group then received one of two test arrays. As can be seen in Table 1, all groups were tested for their fear of a target stimulus and the CS-, the latter stimulus being the same for all four groups (light). The target stimulus was either a light-tone compound (Groups LT-LT and T-LT) or a tone alone (Groups LT-T and T-T). Performance during the target and during the CS- was compared (discrimination measure), and performance during each of these stimuli was compared to a nonstimulus baseline period (general suppression measure). The performance of Groups LT-LT and T-T allowed us to assess the relative degree of learning for both discrimination problems. The performance of Groups LT-T and T-LT was intended to reveal potential differences in the nature of the representational content used by adult and immature rats in solving the two discriminations.

\section{Method}

Subjects. The subjects were 64 preweanling (17 days of age) and 36 adult (60-80 days of age) male and female Sprague-Dawley rats. Approximately equal numbers of males and females were tested at each age. The animals were taken from the colony at SUNYBinghamton. The adults and preweanlings were selected from nine different litters (differences in the number of preweanlings and adults resulted from an attempt to sample from the same number of litters at the two ages; the number of animals available within these litters, however, was greater for preweanlings than for adults, and the additional preweanlings were tested rather than sacrificed). Sixteen preweanlings and 9 adults were randomly assigned to each of the four test conditions. Preweanlings were group-housed in plastic maternity cages with both parents, and adults were individually housed in stainless steel hanging cages. All animals were located in a climate-controlled vivarium, maintained on a 16:8-h light:dark cycle. All experimental testing was confined to the light portion of the cycle. Free access to food and water was provided throughout the experiment.

Apparatus. The apparatus consisted of an animal isolation chamber, inside dimensions measuring $56 \mathrm{~cm}$ (length) $\times 40 \mathrm{~cm}$ (width) $\times 46 \mathrm{~cm}$ (height). One of two grid floors was placed inside the chamber. The grids for the preweanlings were $0.3 \mathrm{~cm}$ in diameter, spaced $0.5 \mathrm{~cm}$ apart, edge to edge; the grids for the adults were $0.7 \mathrm{~cm}$ in diameter, spaced $1 \mathrm{~cm}$ apart. The grids were attached to a $36-\mathrm{cm}$ plastic frame, which was raised $5 \mathrm{~cm}$ from the floor of the chamber. Fresh pine shavings were placed under the grid floor. The grid floors were attached to a Grason-Stadler shocker, which provided $0.5-\mathrm{sec}, 1-\mathrm{mA}$ scrambled shock.

A $36 \times 33 \mathrm{~cm}$ floorless box (35-cm wall height) was placed on top of the grid floor during conditioning. This unit was partitioned, by clear plastic inserts, into three equal-sized subunits, each $36 \times 11 \mathrm{~cm}$. A similar box was used during testing, with the exceptions that it did not contain partitions and that an activitymonitoring device was attached to the front wall. This device was modeled after that described by Moye and Rudy (1985). It consisted of a circular ultrasonic transmitter and a receiver, each $2.4 \mathrm{~cm}$ in diameter. The two components were placed $2.5 \mathrm{~cm}$ above the grid floor and were spaced $5.0 \mathrm{~cm}$ apart. Air-current disturbances, resulting from movement of an animal within the chamber, are detected as frequency discrepancies by the receiver, and initiate closure of an electromechanical relay. Relay closures are counted and recorded by electromechanical counters. Movement of an animal within the chamber is positively correlated with the number of activity counts registered. The sensitivity of the device was tuned by the procedure described by Moye and Rudy.

The test stimuli consisted of a constant $1000-\mathrm{Hz}$ pure tone $(89 \mathrm{~dB})$, presented through a speaker located in the front of the isolation chamber. The light stimulus consisted of a pulsating 7.5-W lamp, centered in the ceiling of the isolation chamber directly over the grid floor. The light flashed at a 0.2-sec rate. A 2.1-W lamp was located in front of the isolation chamber to provide constant dim illumination throughout the chamber. All stimulus events were controlled by a Commodore 64 computer and a locally constructed computer interface.

Procedure. Each subject received one conditioning session and one test session, separated by $24 \mathrm{~h}$. Three rats of the same age were conditioned together. Each rat was placed in one of the sections of the partitioned chamber, with the grid floor appropriate for the age of the subject. Each session contained $24 \mathrm{CS}+$ trials and 24 CS- trials, arranged in a random order. The subjects in all four conditions were given light alone as the CS-, and the CS+ consisted of either a simultaneous light-tone compound or a tone alone, as indicated in Table 1. All stimulus presentations were $15 \mathrm{sec}$ in duration. A 1-mA footshock was presented during the last $0.5 \mathrm{sec}$ of each CS+ presentation. Each stimulus presentation was separated by a random intertrial interval (VI1-45 sec).

The subjects were tested individually $24 \mathrm{~h}$ after conditioning. The test procedure consisted of placing the rat in the test box and measuring activity counts during a 6-min interval. The test interval was divided into six 1-min segments, with each segment associated with a specific stimulus event. Stimulus durations during testing were extended to $60 \mathrm{sec}$ in order to provide a more sensitive index of general activity. Prior research had indicated that $15 \mathrm{sec}$ of stimulus exposure was not sufficient to distinguish stimulus-controlled differences in activity. The sequence of stimulus events was as follows: no stimulus-no stimulus-(target or $\mathrm{CS}-$ )-no stimulus-no stimulus-(target or CS-). The two counterbalanced versions of this sequence differed only with respect to the order in which the target and the CS- appeared. The two test sequences were balanced within each of the four experimental conditions. The total number of activity counts was recorded separately for each of the six stimulus segments. The nature of the target for each of the four experimental conditions is given in Table 1; it was either a simultaneous lighttone compound or a tone alone.

\section{Results}

The primary dependent measure of the test phase of the experiment was the degree to which the subjects discriminated the target stimulus from the $\mathrm{CS}-$. A discrimination score was computed for each subject according to the following formula: activity counts during the target divided by the sum of the activity counts during the tar- 
get and the CS- . According to this measure, scores less than .5 indicate discriminative performance (less activity during the target than during the CS-). Mean discrimination scores for each of the four preweanling and adult groups are presented in Figure 1.

It can be seen that the pattern of results for the preweanlings differed from that of the adults. For adults, discrimination scores were equivalent across the four groups $[F(1,32)=3.3, p>.05]$. The mean score for each group was significantly lower than a value of .5 , indicating a significant discrimination in each condition.

In contrast, the preweanlings' performance revealed an interaction between the nature of the $\mathrm{CS}+$ and the nature of the target stimulus, as tested by a two-way analysis of variance [CS+ (LT vs. T) $\times$ target (LT vs. T) interaction term, $F(1,60)=15.8, p<.001]$. Individual group comparisons (Fisher test; Keppel, 1982) revealed that Group LT-LT expressed a stronger discrimination than Group LT-T, and that a stronger discrimination was found in Group T-T than in Group T-LT. Relative to a value of .5, only Groups LT-LT and T-T showed evidence of a significant discrimination. These results indicate that when the target stimulus differed from the $\mathrm{CS}+$, preweanlings were less able to discriminate the target from the CS-. In other words, the preweanlings treated as quite different the light-tone during conditioning and the tone during testing, and vice versa.

We also measured independently the degree of conditioned fear of the CS - and of the target. Standard suppression ratios were calculated for each subject using the following formula: amount of activity during the target (or $\mathrm{CS}-$ ) divided by the sum of the activity during the target (or CS-) and that during the preceding nonstimulus period. According to this measure, a score significantly lower than .5 indicates that the subject was less active during the stimulus period than during the nonstimulus

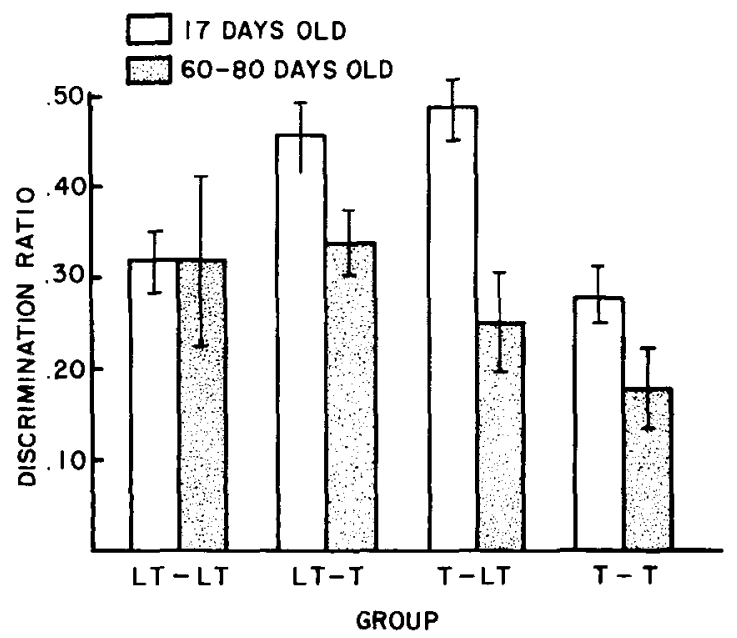

Figure 1. Mean discrimination scores for the four groups of preweanlings and adults tested in Experiment 1. (The CS+ is designated by the letters before the hyphen, and the target stimulus is designated by the letters after the hyphen; $\mathrm{L}=$ light, $\mathrm{T}=$ tone). Lower scores indicate more discrimination.
Table 2

Mean Suppression Scores to the CS- and the Target Stimulus in Experiment 1

\begin{tabular}{lcc}
\hline Group & CS & Target \\
\hline & Adults & \\
LT-LT & .41 & .19 \\
T-T & .54 & .22 \\
LT-T & .48 & .30 \\
T-LT & .50 & .26 \\
& Preweanlings & \\
LT-LT & .38 & .19 \\
T-T & .58 & .30 \\
LT-T & .37 & .30 \\
T-LT & .54 & .45 \\
\hline
\end{tabular}

Note $-\mathrm{L}=$ light, $\mathrm{T}=$ tone.

period. Suppression scores for adults and preweanlings on both the target and the CS- tests are presented in Table 2.

An analysis of variance revealed that among adults, the four groups did not differ on either the target or the CStest. All adult groups suppressed activity during the target, and none of the adult groups suppressed activity during the CS-.

The preweanling groups differed, however, in terms of the amount of suppression to both the CS- $[F(1,60)=$ $20.7, p<.001]$ and the target $[F(1,60)=15.5, p<$ $.001]$. The groups conditioned with a light-tone CS+ (Groups LT-LT and LT-T) were significantly less active during the $\mathrm{CS}-$ than during a nonstimulus period. In contrast, the two groups conditioned with a tone CS+ (Groups T-LT and T-T) were as active during the CS- as during its absence. Also, the degree to which activity was suppressed during the CS- did not differ between Groups LT-LT and LT-T. With respect to performance during the target, only the preweanlings in Group T-LT failed to suppress activity. The remaining three groups also differed in their degree of suppression to the target. The following group comparisons, ordered from most suppression to least, differed significantly: LT-LT $>$ LT-T $=$ T-T > T-LT.

\section{Discussion}

The preweanlings and adults acquired both the featurepositive and the simple discriminations, and did so to a nearly equal level of proficiency. Test performance at the two ages was different, however, suggesting that the preweanlings and adults relied on different representations to solve these problems. The pattern of results for the adults is consistent with the conclusion that they processed the light-tone compound in an elementistic fashion (Kehoe \& Gormezano, 1980). There was no difference in the degree to which the four adult groups discriminated the target from the CS-; they all showed greater fear of the target than of the light. In addition, relative to nonstimulus baseline periods, all four adult groups displayed substantial fear of the target and none showed significant fear of the CS - . The simplest interpretation of these findings is that the adults acquired significant fear of the tone, 
whether it was presented alone or in compound with the light during training; during testing, they then expressed fear of either the tone alone or the light-tone compound. Of course, this is an adaptive strategy, given that the tone was the best predictor of footshock for both discrimination problems.

The preweanlings, despite showing good evidence of having acquired both of the discriminations, were profoundly affected by changing the target stimulus from that of the original CS+ . Preweanling Groups LT-T and T-LT showed no greater fear of the target than of the CS-. This implies that they treated the tone alone as being distinctly different from the tone element of the compound. This is consistent with the possibility that the preweanlings engaged in configural processing, in which the light and tone elements were perceived as an inseparable unit. This may have led them to react differently to the tone when it was an element than when it was in compound with the light. A similar conclusion has been reached for ontogenetic differences in the processing of flavor-flavor and odorflavor compounds (Kucharski \& Spear, 1985; Spear \& Kucharski, 1984a). These results jointly describe the immature rat as being much less selective than the adult in the processing of stimuli.

Another important difference between the preweanlings and adults in this experiment was the level of fear expressed to the target and to the light-alone CS-. On the basis of a comparison between activity during either the target or the CS- and activity during a nonstimulus period, all of the adult groups showed substantial fear of the target and none showed fear of the CS-. In contrast, the preweanlings in Group T-LT failed to show significant fear of the compound, which is consistent with the configural hypothesis. Inconsistent with this hypothesis, however, is the fear of the tone displayed by the preweanlings in Group LT-T and the fear of the light CS- found in the groups trained with the light-tone compound (Groups LT-LT and LT-T). If the younger rats configured the light-tone compound and processed it as a distinctly different stimulus from a tone alone or a light alone, then these latter effects would not be expected.

An alternative explanation of these results, which may be compatible with the configural hypothesis, is based on the assumption that there are two components of stimuluscontrolled fear. One component involves stimulus-specific attributes, in which conditioned fear accrues to a specific stimulus value or dimension-the source of the physical energy that is uniquely transduced as a sound, sight, smell, and so forth. This would include interdimensional attributes (i.e., light or sound) as well as intradimensional attributes (i.e., the specific wavelength of a light or frequency of a tone). The other component involves stimulus-nonspecific attributes. These attributes correspond to features of a stimulus that are either amodal or nondimensional, such as subjective intensity, novelty, duration, spatial localizability, suddenness of onset and offset, and hedonic properties. The argument is that in addition to configural processing, another way in which preweanlings may manifest their tendency to process stimuli less selectively than adults is in terms of the degree to which conditioned fear accrues to nonspecific attributes. Preweanlings may be strongly inclined to include nonspecific attributes in their representation of a fear-evoking stimulus, whereas adults may be strongly inclined to select only the most meaningful attributes: those features that uniquely define the stimulus. For example, the fear of the CS - observed in Preweanling Groups LT-LT and LT-T may reflect the tendency to which these animals conditioned to the nonspecific attributes of the CS+ that were shared by the CS-

One of the most important stimulus-nonspecific attributes is subjective intensity. Recent research by Turkewitz and his colleagues (Turkewitz, Gardner, \& Lewkowicz, 1984; Turkewitz \& Mellon, 1989) has indicated that in immature humans and rats, stimulus intensity serves as a primary, if not the primary, attribute governing stimuluscontrolled behavior. Consequently, the preweanlings may have encoded intensity as a primary representational attribute, whereas the adults may have ignored this feature of the stimulus in focusing more on stimulus-specific features (i.e., light vs. tone). If it is assumed that the lower the intensity of a CS+ the less fear will accrue to the intensity attribute, and that the subjective intensity of a lighttone compound is greater than that of a tone alone, then the pattern of results for the preweanlings may be explicable. Specifically, greater fear of stimulus intensity may have developed in the preweanlings conditioned with the compound CS+ (Groups LT-LT and LT-T) than in the preweanlings conditioned with the tone CS+ (Groups T-T and T-LT). The fear associated with stimulus intensity in the former two groups could have been aroused during testing by presentation of the tone, the light, or the compound, with greater fear expected to the compound than to the light or the tone separately, reflecting generalization decrement. This essentially describes the pattern of responding by preweanlings in Groups LT-LT and LT-T. The absence of fear of the light in the groups trained with the tone CS+ (Groups T-T and T-LT) may indicate that this intensity of the tone alone was insufficient to allow these animals to encode intensity, which implies that they relied instead on stimulus-specific attributes to represent the CS+. This analysis assumes that intensity matters more for preweanlings than it does for adults, and that the intensity of a stimulus during encoding is more important than the intensity of a test stimulus, assumptions that do have some empirical support (Turkewitz \& Mellon, 1989) and which we are currently investigating.

This complex pattern of results underscores the value of using both a discrimination measure and an absolute measure of conditioned fear. Had only the degree of conditioned suppression to the target stimulus been considered, a vastly different conclusion would have emerged than that forced by the discrimination scores. By comparing the relative fear elicited by the target stimulus and the CS-, more information is available than if only fear of the target is considered. 


\section{EXPERIMENT 2}

Another plausible explanation for some of the ontogenetic differences discovered in Experiment 1 involves the idea of generalization decrement. When the target stimulus was different from the original CS + , the relatively weak transfer of conditioning among preweanlings may have been due to their weaker generalization between the compound and an element. A prevalent finding in animal learning is that when test conditions are altered from that of original training-including variations in stimulus characteristics-performance is often disrupted, and this effect is frequently labeled generalization decrement (often erroneously; see Spear, 1978, 1981). If the circumstances were conducive to less stimulus generalization by preweanlings than by adults, as sometimes seems to be the case (e.g., Frieman, Warner, \& Riccio, 1970; but seem Campbell \& Haroutunian, 1983; Rudy \& Hyson, 1984), preweanlings might be expected to show greater disruption in learned performance upon a change in stimulus characteristics than would adults.

As a preliminary test of this hypothesis-that the pattern of results in Experiment 1 was due to greater stimulus generalization in adults than in preweanlings-a simple conditioning procedure was used in Experiment 2. Preweanlings and adults were conditioned with a CS+ consisting of a light-tone compound; a CS- was not employed. Separate groups at each age were then tested with a single stimulus - a light-tone compound, a tone alone, or a light alone. If preweanlings characteristically show less stimulus generalization than do adults, then preweanlings should show less fear than adults of the light or the tone, relative to the light-tone compound.

\section{Method}

Thirty-six preweanlings and 36 adults were randomly assigned to each of three conditions $(n=12)$. At each of the two ages, the subjects were taken from four different litters. The same apparatus and general procedure used in Experiment 1 were again employed. Each subject received $24 \mathrm{CS}+$ trials on a VI-90 sec schedule, with a $0.5-\mathrm{mA}$ footshock presented during the last $0.5 \mathrm{sec}$ of each CS+. All subjects were conditioned with a simultaneous light-tone compound $\dot{\mathrm{C}}+$. Testing was completed $24 \mathrm{~h}$ after conditioning. The six 1-min test intervals were arranged in the following sequence: no stimulus-no stimulus-(target)-no stimulus-no stimulus-(target). The target stimulus was varied between groups. Group LT was tested with the original light-tone compound, Group $T$ was tested with the tone alone, and Group $\mathrm{L}$ was tested with the light alone. A suppression ratio was computed for each subject according to the following formula: the number of activity counts during the target divided by the sum of the activity counts during the target and the no-stimulus period that immediately preceded the target. The degree of conditioned fear to the target stimulus is inversely related to this suppression ratio.

\section{Results and Discussion}

Mean suppression ratios for the adult and preweanling groups are presented in Figure 2. It can be seen that conditioned fear was equivalent for the adults and preweanlings when the target and the CS were identical (LT groups) and was less likely to be expressed to a different

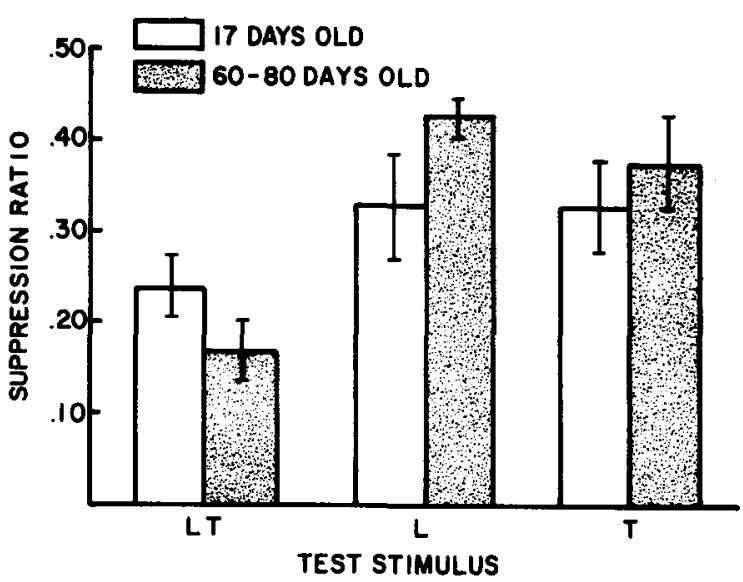

Figure 2. Mean suppression scores for the three groups of preweanlings and adults tested in Experiment 2. Lower scores indicate more suppression.

target (L or T groups). The important observation, however, is that there is no evidence that the preweanlings manifested less stimulus generalization than did the adults. An age $\times$ group analysis of variance revealed that suppression scores did not differ as a function of age $[F(1,66)=.43, p>.5]$, but did differ across the three test conditions $[F(2,66)=15.5, p<.001]$; the age $\times$ group interaction was not significant $[F(2,66)=2.7, p>$ .1]. Individual group mean comparisons revealed that the amount of suppression in preweanlings and adults tested with the light (Group L) and the tone (Group T) was equivalent, and was significantly less than the suppression found in subjects tested with the light-tone compound (Group LT). These data suggest that it is unlikely that the pattern of results in Experiment 1 was due to less stimulus generalization by preweanlings than by adults. These results, of course, do not rule out the possibility of an ontogenetic difference in generalization decrement, but such an interpretation would require a much more complicated view of generalization than has typically been assumed in order to capture the effects of Experiments 1 and 2.

We also need to comment on the contrast between the results of Experiments 1 and 2 as they relate to the configural hypothesis. If it is the case that preweanlings configure light-tone compounds and treat a compound as distinct from its constituent elements, then conditioned fear would not be expected in Preweanling Groups T and L. Although less fear was evident in these groups than in Group LT, the fear expressed to the light and tone elements was substantial. In contrast, the discrimination scores in Experiment 1 for Preweanling Group LT-T revealed that these animals showed no greater fear of a tone by itself than of the light CS-, which would be consistent with the configural hypothesis. The apparent discrepancy is easily resolved. Although the latter subjects showed no greater fear of the tone than of the light, there was substantial fear expressed to both the tone and the light, relative to nonstimulus baselines. Thus, fear of the 
tone was evident in both experiments among preweanlings trained with a light-tone CS+; in Experiment 1, however, even greater fear was expressed to the light-tone compound. It can again be argued that the fear of the tone and light found in Experiment 2 reflects the degree to which the preweanlings developed a fear of stimulusnonspecific attributes shared by the compound and the elements. The implications of this possibility for the configural hypothesis will be considered in the General Discussion.

Another discrepancy between the results of Experiments 1 and 2 concerns the level of fear expressed by adults. In Experiment 1, adults trained on the feature-positive discrimination ( $\mathrm{LT}+/ \mathrm{L}-$ ) displayed as much fear of the light-tone compound (Group LT-LT) as of the tone alone (Group LT-T). In Experiment 2, adults trained with the light-tone compound displayed significantly less fear of the tone alone than of the compound. This discrepancy may involve a sampling error between the two experiments, but a more likely explanation, and one for which there are interesting theoretical implications, is that the procedural differences between the experiments may have been responsible for the obtained differences. Specifically, the discrimination training in Experiment 1 may have made the adults more inclined to select the tone element as the more relevant stimulus feature, given that the light element predicted shock with a probability of .5 , whereas the tone perfectly predicted shock. In Experiment 2, both the light and the tone were perfectly correlated with shock, and this may have reduced the degree of fear that accrued to the tone, relative to that obtained in Experiment 1. This does not imply that the adults in Experiment 2 necessarily relied on configural processing-the appropriate control groups were not included to allow for such a determination-nor is it logically inconsistent to hold that elementistic processing could have been used by the adults in Experiment 2. The degree to which elementistic processing may be enhanced by discrimination training is, however, an interesting question.

\section{EXPERIMENT 3}

It has been shown that adult rats process compounds in feature discriminations differently when the elements are presented simultaneously than when they are presented sequentially (Holland, 1985). The temporal arrangement of the elements within a compound has also been found to affect stimulus processing in younger rats (Kucharski \& Spear, 1985). The temporal arrangement of elements may have a particularly pronounced impact on younger rats. When the elements of a compound are presented sequentially, ontogenetic constraints on perception, memory, or both may make it difficult for younger rats to represent the nexus of these elements; they may thus fail to process the elements as a compound.

In Experiment 3, we examined the impact of temporally separating the elements of a compound in preweanlings and in adults. Subjects were trained on a serial feature- positive discrimination. The $\mathrm{CS}+$ consisted of a sequential presentation of a light and a tone. In Experiment 1, there was clear evidence that when the elements of the compound occur simultaneously, preweanlings can acquire a feature discrimination, and do so about as well as adults. Experiment 3 was designed to determine whether or not preweanlings are equally facile with serial compounds, and to what extent, if any, adults and preweanlings would behave differently.

\section{Method}

The same general procedure used in Experiment 1 was again followed. The major exceptions involved the nature of the CS+ and the limitation that only one of the four stimulus conditions tested in the first experiment was included here; all subjects $(n=15$ preweanlings and 15 adults) were conditioned and tested with the same compound CS+. The CS- again consisted of a 15-sec light presentation. The CS+ was a 15 -sec tone, followed immediately by a 15-sec light, with footshock presented during the last $0.5 \mathrm{sec}$ of the light. Each subject received $24 \mathrm{CS}+$ and $24 \mathrm{CS}-$ trials arranged randomly. Testing occurred $24 \mathrm{~h}$ after conditioning. The test sequence was composed of the following stimulus events, arranged in the order listed: no stimulus-(light)-no stimulus-(tone)(light). Each stimulus presentation within a sequence was $15 \mathrm{sec}$ in duration, and each nonstimulus period was $30 \mathrm{sec}$ in duration. The entire sequence was repeated four times in succession during the test period. Cumulative activity counts were recorded separately for each of the five segments of the test sequence. Although each stimulus duration during testing was shortened from the 60 -sec value used in Experiments 1 and 2, in order to maintain the temporal property of the sequential compound used during conditioning, the four presentations of each stimulus yielded a total stimulus exposure of $60 \mathrm{sec}$, which provided an adequate interval to measure and compare activity across stimulus conditions.

\section{Results and Discussion}

A discrimination score was calculated for each subject according to the following formula: the number of activity counts during light-after-tone presentations divided by the sum of the activity counts during light-alone presentations and light-after-tone presentations. The mean discrimination scores for preweanlings and adults appear in Figure 3.

Discrimination scores for adults were found to be significantly lower than the discrimination scores for preweanlings $[t(28)=3.54, p<.05]$. Also, the scores for adults were significantly lower than .5 , indicating that the light-alone CS- was discriminated from the lightafter-tone CS+. The scores for the preweanlings were not statistically different from .5, indicating a failure to discriminate the light-alone from the light-after-tone presentations.

The results of this experiment contrast with those of Experiment 1 . In the first experiment, preweanlings and adults both acquired a simultaneous feature-positive discrimination, and performed equally well. In Experiment 3, preweanlings showed no evidence of learning a serial feature-positive discrimination, whereas adults did express such learning. It should be emphasized that despite the fact that the preweanlings and adults received the same amount of training, which was also true in Experiment 1, 


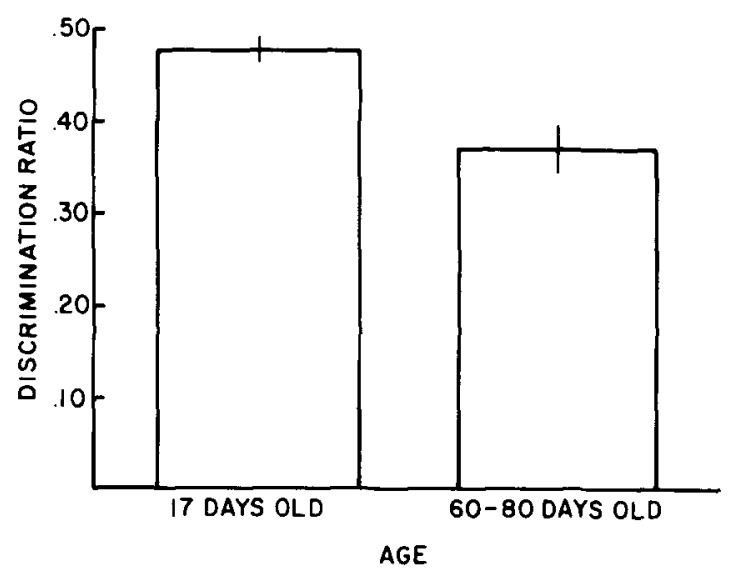

Figure 3. Mean discrimination scores for preweanlings and adults trained on the serial feature-positive discrimination in Experiment 3. Lower scores indicate more suppression.

the age-related difference could represent a parametric constraint, rather than an ontogenetic constraint. Perhaps with more extended training preweanlings would express the discrimination. Thus, we do not want to interpret these results as an indication that preweanlings cannot acquire a serial feature-positive discrimination. Yet it does appear that the preweanlings' ability to do so is at least inferior to that of adults and contrasts with their performance with a simultaneous feature-positive discrimination.

\section{GENERAL DISCUSSION}

Our major finding was that preweanling and adult rats seem to process light-tone compounds differently. In Experiment 1 , this difference was reflected in the ability of the younger and older rats to discriminate a light CSfrom a target stimulus, which was either a simultaneous light-tone compound or a tone by itself. The target was either the same or different than the CS+ (compound or element). Adults in all four groups were equally good at discriminating the CS- from the target. The preweanlings, in contrast, were severely disrupted when the target stimulus differed from the CS + , although their performance was equal to that of the adults when the target was the same as the CS + . Adults and preweanlings also differed in their degree of absolute suppression to the target and CS-, which was measured by comparing activity during and before the respective stimulus presentations. All adult groups showed equal suppression to the target, and none of the adult groups suppressed activity during the CS-, which is consistent with their discrimination scores. The preweanlings, however, showed a different pattern. Suppression to the target was found not only in the two groups tested with the CS+ as the target, but also in the group conditioned with the compound and tested with the tone as the target (Group LT-T). In addition, the two preweanling groups conditioned with the compound suppressed activity even during the $\mathrm{CS}-$, but the two groups conditioned with the tone alone did not. Finally, in Experiment 3, adults were found to acquire a serial feature-positive discrimination, in which the tone and light elements were presented successively, but there was no evidence of acquisition of this discrimination by preweanlings.

Several alternative explanations can be considered for this complex pattern of ontogenetic differences. The alternatives differ primarily in terms of their assumptions concerning the manner in which compound stimuli are processed and the mechanism held to be responsible for the age-related differences. The mode-of-processing hypothesis involves a distinction between elementistic and configural processing. Elementistic processing consists of decomposing a compound into its constituent elements, so that conditioning accrues to each of the elements independently. With configural processing, the elements are combined, and the combination is processed as a single stimulus (Kehoe \& Gormezano, 1980). There is evidence that animals can use either type of processing. Whether elementistic or configural processing occurs seems to depend on the experimental parameters and the nature of the overall stimulus experience (Kehoe, 1982, 1986; Kehoe \& Grahm, 1988). The results of recent ontogenetic studies also indicate that age can influence the tendency to rely on one mode of processing or the other. The general trend in these studies has been for younger rats to behave as if they are more inclined to configure compounds, and for adults to behave as if they are more likely to rely on elementistic processing (Kucharski \& Spear, 1985; Spear \& Kucharski, 1984b).

Mode of processing compound stimuli may be relevant to the present findings. In Experiment 1, adults responded to a tone by itself in the same way that they responded to a tone presented in compound with a light, which is consistent with elementistic processing. The tone was the best predictor of shock in all groups, and the adults could have reacted to this by decomposing the light-tone compound presented during conditioning or testing. This would have allowed them to acquire and express conditioned fear of the tone. The discrimination scores for adults and their absolute suppression to the CS- and the target are consistent with this account. The preweanlings, however, may have configured the light-tone compound. This is indicated in Experiment 1 by their failure to discriminate the CS- from a target that differed from the original CS+. It was as if they responded to a light-tone compound as a distinctly different stimulus from a tone by itself. The preweanlings' failure to acquire the serial feature-positive discrimination in Experiment 3 might indicate that when the elements are temporally separated, they fail to configure. Without a configured $\mathrm{CS}+$, they could not have solved the discrimination in the same way that they solved the simultaneous feature-positive problem, which may account for their failure to learn. It is also possible that the preweanlings were unable to utilize the occasion-setting function of the tone, as adults seem to have done. In the serial compound, the tone provides a conditional cue that allows occurrences of the second 
serial element to be distinguished from presentations of that element in isolation. Adult rats have been shown to utilize this relation in responding selectively to compounds and their elements (Holland, 1985). Whether younger rats are generally unable to learn conditional relations between serial events, due perhaps to perceptual or memorial limitations, or whether these relations are just more difficult to learn, so that with more extended training they might solve the serial feature-positive discrimination, requires further investigation.

There are some problems with the mode-of-processing explanation. It has difficulty accounting for the differences between preweanling and adults in the levels of absolute suppression to the CS- and the target in Experiment 1, and in explaining the degree of generalized fear of the tone and the light in Experiment 2. An alternative explanation may be that immature rats are more inclined than adults to encode nonspecific attributes of a stimulus. This disposition is implied in a variety of effects reported by Spear and Molina (1987) and by Spear, Kraemer, Molina, and Smoller (1988). It may reflect an extension of the more general principle that younger rats are less selective than adults in the manner in which they process stimuli.

Subjective intensity seems to be one of the more important nonspecific attributes to which both infant rats and infant humans attend, a disposition that appears to diminish with age (Turkewitz \& Mellon, 1989). If the preweanlings, but not the adults, encoded relative intensity as a primary stimulus attribute, or perhaps as the most salient attribute, then the results of the present experiments may reflect this ontogenetic trend. For example, it could account for why preweanlings failed to discriminate targets that differed from the original CS+ (these targets differed in relative intensity from that of the $\mathrm{CS}+$ representation); why preweanlings but not adults trained with a compound $\mathrm{CS}+$ in Experiment 1 showed fear of the light (the subjective intensity of the light may have been sufficient to activate the intensity attributes of the CS+ representation); why preweanlings trained with a light-tone compound in Experiment 2 displayed some fear of the tone and light elements (again, processing may have been guided primarily by the intensity attribute, allowing for the intensity of the tone and light to activate the CS+ representation, albeit less effectively than would the CS+ itself); and why preweanlings failed to acquire the serial feature-positive discrimination in Experiment 3 (by concentrating on the intensity attribute, they would have perceived the light element of the compound as equivalent to the light CS- , rendering discrimination between the two light presentations difficult or impossible).

The intensity hypothesis and the configural hypothesis are not mutually exclusive. The tendency for immature rats to encode stimulus-nonspecific attributes may itself involve a form of configural processing. By failing to differentiate attributes such as intensity from stimulusspecific properties, it could be argued that the younger rat processes these features as a configural compound; the adults' tendency to select the more meaningful stimulus-specific attributes may indicate that at this age, specific and nonspecific attributes are treated as separable components of a stimulus (Garner, 1970). If indeed the preweanlings summate the subjective intensity of a tone and light presented simultaneously, then the lighttone compound could be regarded as a configural stimulus. The important point, however, is that a tendency toward configural processing, and a tendency toward encoding stimulus-nonspecific attributes, are both indicative of less selective processing. Whether a fundamental distinction can be drawn between configural processing and stimulus-nonspecific processing requires additional study and consideration, but the point we wish to emphasize is that the present data do suggest that the younger rat is less selective than the adult in processing stimuli, even if the precise mechanism for this tendency remains speculative.

Other explanations for our results are also plausible. None of the alternatives, however, seem as adequate or as parsimonious as either the mode-of-processing hypothesis or the intensity hypothesis. One alternative assumes that at both ages, rats rely on elementistic processing, but preweanlings are simply more likely than adults to show stimulus generalization decrement. The failure of the preweanlings tested in Experiment 1 to discriminate the target from the CS-, whenever the target differed from the CS+, is consistent with this idea. The results of Experiment 2 , however, do not support the assumption that preweanlings will typically show greater stimulus generalization decrement. In Experiment 2, all preweanlings and adults were conditioned with a compound CS + , and separate groups at each age were then tested with the compound, the light alone, or the tone alone. Rats at both ages displayed less suppression to the elements than to the original compound, and the magnitude of the differences did not vary as a function of age. A second factor counting against the generalization decrement hypothesis is that it cannot account for the pattern of responding to the CSfound in the preweanlings.

A second alternative is that the preweanlings reacted to the partial reinforcement aspect of the feature-positive discrimination and the adults did not. The idea is that the preweanlings conditioned with the light-tone compound may have relied on elementistic processing just as the adults did, but in addition they showed a partial reinforcement effect in conditioning to the light. This could explain the suppression to the light found in the two groups conditioned with the light-tone compound: the light was reinforced on $50 \%$ of its exposures, whereas the tone was reinforced each time it was presented. Thus, some fear of the light would be expected, but it should be less than that found to the tone. This would explain why the rats in Group LT-LT showed greater suppression to the compound than to the light, although they did suppress to the light itself. This explanation can also account for the failure to observe suppression to the light in the two preweanling groups conditioned with a tone CS + . In these groups, the light was never reinforced. The problem with 
this explanation is that it cannot readily account for the failure of the preweanlings to discriminate the target from the $\mathrm{CS}-$ when the target differed from the original CS+. The partial reinforcement hypothesis assumes that the preweanlings engaged in elementistic processing, so that when tested with targets that differed from the CS+ they should have been as proficient at discriminating the target from the CS- as they were when the target was the $\mathrm{CS}+$; the data were otherwise. This hypothesis cannot be saved by the additional assumption that the preweanlings showed greater generalization decrement than did the adults when the target differed from the CS+; the data from Experiment 2 do not support this assumption. Also, if it is assumed that both the preweanlings and the adults relied on elementistic processing, then some additional mechanism would be required to account for the failure of the preweanlings but not the adults to acquire the serial feature-positive discrimination in Experiment 3.

Another possibility is that the preweanlings but not the adults formed within-compound associations between the light and the tone when conditioned with the compound in Experiment 1. This could account for the suppression found to the light in Groups LT-LT and LT-T. Presentation of the light could have evoked the representation of the tone, which could have in turn elicited some response suppression to the light. A failure to observe suppression to the light in Groups T-T and T-LT would then also be expected, given that the light would not elicit the representation of the tone. Some additional assumptions would then be required to account for the effects of testing preweanlings with targets that differed from the original CS+. Again, the assumption that preweanlings show greater stimulus generalization decrement than do adults may be logically acceptable, but the assumption does not fit the facts of Experiment 2 and is not supported by most other tests (Campbell \& Haroutunian, 1983; Rudy \& Hyson, 1984). It would also be necessary to invoke an additional mechanism to explain the age-related differences found with the serial compound in Experiment 3.

Finally, recent models of stimulus processing, which have been advanced to account for adult phenomena of compound conditioning, do not seem to offer any obvious explanation for the ontogenetic differences obtained in this and other studies. Pearce's (1987) generalization model could accommodate some of our results for the preweanlings and adults taken separately, but it fails to provide an explanation for the ontogenetic differences themselves. This is also true of Kehoe's (1988) layered network model; although it contains valuable insights regarding configural and elementistic processing of stimulus compounds, it provides no obvious mechanism to account for the age-related differences of the type discovered in our experiments. The ability of any contemporary model of stimulus processing to explain ontogenetic differences will certainly enhance the value of such a model. The degree to which age-related differences can be captured by a model may be a valuable criterion by which to judge its adequacy.
In addition to pertinent theoretical questions, our results are also of more general relevance. The procedure used in the present experiments was adopted from Moye and Rudy (1985). They showed that general activity can be a sensitive behavioral measure for assessing Pavlovian conditioning in immature rats. Our results indicate further that the same procedure is as effective in studying conditioning in adults. The procedure has numerous advantages and great potential as a strategy for testing learning and memory in rats of various ages. Suppression of general activity is a behavioral measure that has a high degree of ecological validity (Bolles, 1970), and by using the ultrasonic motion detector, performance can be assessed in a very unobtrusive manner. The test procedure also affords the opportunity to make ontogenetic comparisons with a variety of stimuli, including visual, auditory, and olfactory. It seems to be a particularly wellsuited technique for studying complex learning in younger and older rats, of the type exemplified by the feature discriminations investigated here. We are optimistic that future investigation with this procedure will not only clarify the theoretical issues raised by the present study, but may yield valuable new empirical information concerning the ontogeny of learning and memory.

\section{REFERENCES}

AMSEL, A. (1979). The ontogeny of appetitive learning and persistence in the rat. In N. Spear \& B. Campbell (Eds.), Ontogeny of learning and memory (pp. 189-224). Hillsdale, NJ: Erlbaum.

AMSEL, A. (1986). Developmental psychobiology and behavior theory: Reciprocating influences. Canadian Journal of Psychology, 640, 311-342.

Bachevalier, J., \& Mishrin, M. (1984). An early and a late developing system for learning and retention in infant monkeys. Behavioral Neuroscience, 98, 770-778.

Bolles, R. C. (1970). Species specific defense reactions and avoidance behavior. Psychological Review, 71, 32-48.

CAMPBELL, B. A. (1967). Developmental studies of learning and motivation in infraprimate mammals. In H. Stevenson, E. Hess, \& H. Rheingold (Eds.), Early behavior: Comparative and developmental approaches (pp. 43-72). New York: Wiley.

Campbell, B. A., Coulter, X. (1976). Ontogeny of learning and memory. In M. R. Rosenzweig (Ed.), Neural mechanisms of learning and memory (pp. 209-235). Cambridge, MA: MIT Press.

Campbell, B. A., Haroutunian, V. (1983). Perceptual sharpening in the developing rat. Joumal of Comparative Psychology, 97, 3-11.

Campeell, B.A., \& Spear, N. E. (1972). Ontogeny of memory. Psychological Review, 79, 215-236.

Coulter, X. (1979). The determinants of infantile amnesia. In N. E. Spear \& B. A. Campbell (Eds.), Ontogeny of learning and memory (pp. 245-270). Hillsdale, NJ: Erlbaum.

Frieman, J., Warner, J., Riccio, D. C. (1970). Age differences in conditioning and generalization of fear in young and adult rats. $D e$ velopmental Psychology, 3, 119-123.

GARNER, W. R. (1970). The stimulus in information processing. American Psychologist, 25, 350-358.

Gordon, W. C. (1979). Age: Is it a constraint on memory content? In N. E. Spear \& B. A. Campbell (Eds.), Ontogeny of learning and memory (pp. 271-287). Hillsdale, NJ: Erlbaum.

HINDERliter, C., MISANIN, J. (1988). Weanling and senescent rats process simultaneously presented odor and taste differently than young adults. Behavioral \& Neural Biology, 49, 112-117.

Holland, P. C. (1985). The nature of conditioned inhibition in serial 
and simultaneous feature negative discriminations. In R. Miller \& N. Spear (Eds.), Information processing in animals: Conditioned inhibition (pp. 267-297). Hillsdale, NJ: Erlbaum.

KAIL, R., SPEAR, N. E. (1984). Comparative perspectives on the development of memory. Hillsdale, $\mathrm{NJ}$ : Erlbaum.

KEHOE, E. J. (1982). Overshadowing and summation in compound conditioning of the rabbit's nictitating membrane response. Journal of Experimental Psychology: Animal Behavior Processes, 8, 313-328.

KEHOE, E. J. (1986). Summation and configuration in conditioning of the rabbit's nictitating membrane response to compound stimuli. Journal of Experimental Psychology: Animal Behavior Processes, 12. 186-195.

КЕнОE, E. J. (1988). A layered network model of associative learning: Learning to learn and configuration. Psychological Review, 95, 411-433.

Kehoe, E. J., \& Gormezano, I. (1980). Configuration and combination laws in conditioning of compound stimuli. Psychological Bulletin, 87, 351-378.

Kehoe, E. J., Grahm, P. (1988). Summation and configuration: Stimulus compounding and negative patterning in the rabbit. Journal of Experimental Psychology: Animal Behavior Processes, 14, 320-333.

Keppel, G. (1982). Design and analysis. Englewood Cliffs, NJ: Prentice-Hall.

Kucharski, D., SPEAR, N. E. (1985). Potentiation and overshadowing in preweanling and adult rats. Journal of Experimental Psychology: Animal Behavior Processes, 11, 15-34.

MOYE, T. B., Rudy, J. W. (1985). Ontogenesis of learning. VI: Learned and unlearned responses to visual stimulation in the infant hooded rat. Developmental Psychobiology, 18, 395-409.

NADEL, L., \& Zola-Morgan, S. (1984). Infantile amnesia: A neurobiological perspective. In M. Moscovitch (Ed.), Infant memory (pp. 145-172). New York: Plenum.

Pearce, J. M. (1987). A model for stimulus generalization in Pavlovian conditioning. Psychological Review, 94, 61-73.

Rudy, J. W., \&yson, R. L. (1984). Ontogenesis of learning: III. Variation in the rat's differential reflexive and learned responses to sound frequencies. Developmental Psychobiology, 17, 285-300.

Rudy, J. W., VoGT, M. B., Hyson, R. L. (1984). A developmental analysis of the rat's learned reactions to gustatory and auditory stimulation. In R. Kail \& N. Spear (Eds.), Comparative perspectives on the development of memory (pp. 181-208). Hillsdale, NJ: Erlbaum.

SHEPP, B. E. (1983). The analyzability of multidimensional objects: Some constraints on perceived structure, the development of perceived structure, and attention. In T. J. Tighe \& B. E. Shepp (Eds.), Perception, cognition, and development: Interactional analysis (pp. 39-76). Hillsdale, NJ: Erlbaum.
Spear, N. E. (1973). Retrieval of memory in animals. Psychological Review, 80, 163-175.

SPEAR, N. E. (1978). The processing of memories: Forgetting and retention. Hillsdale, NJ: Eribaum.

SPEAR, N. E. (1979). Memory storage factors in infantile amnesia. In G. Bower (Ed.), The psychology of leaming and motivation (Vol. 13. pp. 91-154). New York: Academic Press.

SPEAR, N. E. (1981). Extending the domain of memory retrieval. In N. Spear \& R. Miller (Eds.), Information processing in animals: Memory mechanisms (pp. 341-378). Hillsdale, NJ: Erlbaum.

SPEAR, N. E. (1984). Ecologically-determined dispositions control the ontogeny of learning and memory. In R. Kail \& N. E. Spear (Eds.), Comparative perspectives on the development of memory ( $\mathrm{pp}$. 325358). Hillsdale, NJ: Erlbaum.

Spear, N. E., CAmpBell, B. A. (1979). Ontogeny of leaming and memory. Hillsdale, NJ: Erlbaum.

Spear, N. E., Kraemer, P. J., Molina, J. C., \& Smoller, D. E (1988). Developmental change in learning and memory: Infantile disposition for unitization. In J. Delacour \& C. S. Levy (Eds.), Systems with learming and memory abilities (pp. 27-52). Amsterdam: Elsevier/ North-Holland

SPEAR, N. E., KUCHARSKI, D. (1984a). Ontogenetic differences in the processing of multi-element stimuli: Potentiation and overshadowing. In H. Roitblat, T. Bever, \& H. Terrace (Eds.), Animal cognition (pp. 545-567). Hillsdale, NJ: Eribaum.

SPEAR, N. E., Kucharski, D. (1984b). The ontogeny of stimulus selection: Developmental differences in what is learned. In R. Kail \& N. Spear (Eds.), Comparative perspectives on the development of memory (pp. 227-252). Hillsdale, NJ: Erlbaum.

Spear, N. E., Molina, J. C. (1987). The role of sensory modality in the ontogeny of stimulus selection. In N. Krasnegor, E. Blass, M Hofer, \& W. Smotherman (Eds.), Perinatal development: A psychobiological perspective (pp. 83-110). Orlando, FL: Academic Press.

Turkewitz, G., Gardner, J. M., \& Lewkowicz, D. J. (1984). Sensory/perceptual functioning during early infancy: The implications of a quantitative basis for responding. In G. Greenberg \& E. Tobach (Eds.), Behavioral evolution and integrative levels (pp. 167-195). Hillsdale, NJ: Erlbaum.

TURKEwitz, G., \& Mellon, R. (1989). Dynamic organization of intersensory function. Canadian Journal of Psychology, 43, 286-301.

(Manuscript received December 1, 1988; revision accepted for publication July $22,1989$. ) 